\title{
A Review of Methods to Control Bleeding from Life-Threatening Traumatic Wounds
}

\author{
Sody Abby Naimer ${ }^{1,2,3}$ \\ ${ }^{1}$ Department of Family Medicine, Siaal Research Center for Family Medicine and Primary Care, Faculty of \\ Health Sciences, Ben-Gurion University of the Negev, Beer-Sheva, Israel \\ ${ }^{2}$ Emergency room, Soroka University Medical Center, Beer-Sheva, Israel \\ ${ }^{3}$ Shomron Hazala Emergency Services, Emergency Ambulance Squad, Lev Shomron, Israel \\ Email: sodyna@clalit.org.il
}

Received 20 December 2013; revised 26 January 2014; accepted 3 February 2014

Copyright (C) 2014 by author and Scientific Research Publishing Inc.

This work is licensed under the Creative Commons Attribution International License (CC BY).

http://creativecommons.org/licenses/by/4.0/

(c) (i) Open Access

\section{Abstract}

The large selection of techniques and modalities for field treatment of the bleeding wound may appear as a potpourri of arbitrarily introduced devices. Nevertheless, if we analyze the various offered solutions systematically in an orderly approach, they can be differentiated into set categories. It is necessary to recognize the pros and cons of each available product in order to decide when and where each is the most applicable for any given clinical scenario. Identification, development and evaluation of new products and technologies capable of stopping life threatening hemorrhage are still ongoing. Despite paucity of research on this topic recently more and more information has accumulated to assist in supporting those techniques of superior efficacy. The objective of this review is to guide the reader through the diverse products according to mechanism of action and expose the important literature relevant to this topic. Justification is found for use of each of the categories: tourniquets, hemostatic agents and compression dressings however close scrutiny is needed to select the most appropriate choice in each group. Hopefully, continuing appraisal of these devices together with the growing experience of trauma teams and combat medics can assist to establish the superior products in each class for the benefit of all casualties and trauma victims.

\section{Keywords}

Bleeding Wound; Trauma; Tourniquet; Hemorrhage; Compression; Hemostatic Agents; Dressings

\section{Introduction}

"The fate of the wounded lies in the hands of the ones who apply the first dressing" was the most famous quote of Dr. Nicholas Senn, the founder of the Association of Military Surgeons of the United States. 
Acute hemorrhage accounts for about $50 \%$ of battlefield deaths in conventional warfare, and for $30 \%$ of casualties who die from wounds [1]-[4]. The most basic of just any form of assistance to the trauma victim is the application of some sort of means to curb blood loss as immediate as feasible following the threatening traumatic event. While many issues regarding the on-scene care of polytrauma patients are still under debate, it is agreed that immediate control of acute external traumatic hemorrhage is one of the sole instances where intervention by the rescue team member plays a decisive role in determining the final outcome of the wounded victim [5]. We all remember the field bandage as a recommended device for wound care presented at the most basic of any first aid course. Exhaustive attempts will fail to discover any formal trial or scientific report validating the advantages or disadvantages of its use. Therefore we cannot establish its limitations, or for that matter, what, if any advantage is conferred with its use. An agreed unprecedented expectation at the outset of the 21st century remains to strive for delivery of evidence based care in all aspects of medicine. This poses a significant challenge. In specific areas of medical care this target renders endeavors extremely difficult if not nearly impossible.

In general, trauma constitutes an arena of research difficult to tackle. It is impossible to obtain informed consent or in fact any consent whatsoever in the framework of acute traumatic injury. Hurdles in exploring trauma issues include: the lack of uniformity of scenarios or uniformity of trauma care delivery teams. The focus on care of the bleeding wound explicitly complicates evaluation of different modes of intervention for numerous reasons. Namely, arrival of teams at different points in time from the instant of injury, unique mechanisms of each injury, lack of specific standards of care of other accompanying medical threats, difficulty of judging outcomes when a multitrauma victim is jeopardized by a number of separate injuries simultaneously etc... Nevertheless we persevere to collect the greatest body of available information in order to justify our rationale of reasoning and clinical behaviour despite the necessity to compromise and lay back on less than ideal evidence.

In the past hundred years the industrial revolution led to discovery of a world of new technology. New materials were invented with practically unlimited potential of consistency, size and shape to suit our needs for all scopes of modern life. In regard to bleeding wounds in particular, following complete dormancy over the first two thirds of the past century when very little has happened, we are now bombarded by many new products all available to achieve the common straightforward target of preventing blood loss from injured soft tissue. In this paper we attempt to categorize each of the techniques as occlusion, barrier, or clotting propagation methods and demonstrate examples of each by prototypes. The examples are by no means conclusive, however, this basic review can serve to guide the perplexed and outline the expectations and pros and cons of each option.

As mentioned, basic science and obviously clinical research is lacking in this field and we must greatly rely on common sense, personal experience and style. To date there are sparse recommendations and no specific product stands out as a superior means to treat bleeding wounds. Therefore humility should overcome the caregiver until we can clearly single out a preferred technique by well controlled trials supporting supremacy of any specific choice. This state of affairs is best put by Hamilton Bailey, a renowned British surgeon who claimed more than seventy years ago: "It is highly desirable that anyone engaged in war surgery should keep his ideas fluid and so be ready to abandon methods which prove unsatisfactory in favour of others which, at first, may appear revolutionary and even not free from inherent danger."

\section{Anatomical Considerations Dictating Solution Criteria}

A general assertion essential to stress before presenting the various devices available to control bleeding from the traumatic wound is that the anatomical region inflicted will dictate the best intervention to choose. The majority of hemorrhagic deaths on the battlefield are due to intracavitary hemorrhage, which as a rule is not readily accessible and cannot be controlled with externally applied methods [6]-[8]. Since regions as torso and penetrating head injuries are not compressible therefore such wounds are not amenable to treatment by any external device. However, in reality many traumatic events result in injuries involving body parts where intervention with external devices is very rewarding. A recent epidemiology study of 6609 combat wounds in Operation Iraqi Freedom (OIF) and Operation Enduring Freedom (OEF) showed that extremities were the most common sites of injury among 1566 casualties (54\%), the majority of which was amendable to tourniquet application [9]. According to the Wound Data and Munitions Effectiveness Team (WDMET) database, exsanguination from extremity wounds accounts for more than half of all potentially preventable deaths in combat [10]. Also, a recent evaluation of autopsy data from nearly 1000 casualties from OEF, OIF revealed that hemorrhage accounted for $85 \%$ of potentially survivable deaths, with $31 \%$ and $69 \%$ of these deaths representing compressible and noncompressible wounds, respectively [11]. Proximal superficial regions overlying skeletal components (such as 
certain head, neck or back areas) are not candidate for tourniquet application but may still gain much from compression dressing or hemostatic devices.

\section{Vascular Occlusion Methods}

\subsection{Pressure Point Compression}

Digital pressure applied over proximal arterial pressure points helps to control bleeding by lowering the pressure at the bleeding site. Performed correctly and, when possible, simultaneously with direct pressure over bleeding site, can partially control significant, even brisk arterial, hemorrhage. There has never been a good method for teaching these techniques to prehospital medical personnel and so when treating hemorrhage in combat or civilian casualties, these personnel often apply insufficient pressure for an insufficient period of time. Unfortunately, no matter how well this task is taught, the circumstances of combat or traumatic arenas make it unlikely, in many cases, that a medical caregiver or corpsman will be able to apply the requisite force long enough to achieve hemorrhage control throughout an average or lengthy evacuation. Despite a recommendation to perform this in many first aid manuals, there is no scientific literature that can support this technique. The subjectivity of pressure application difficult to maintain uniformly upon a time axis and the fact that this method completely neutralizes the caregiver from tending to any other aspect of patient care, including evacuation, puts this modality in last place.

\subsection{Tourniquets}

Historically, from the turn of time this technique has been an established means to affect blood supply to a distant part of a limb. Galen (129 - 200 AD), at the time the most famous surgeon in Rome, was criticized for tourniquet use, fearful it would increase blood loss from a wound. In 1517, Hans von Gersdorff, a founder of Prussian military medicine, published a trauma surgery atlas and described tourniquet use in amputation surgery [12]. In 1593, Wilhelm Fabry of Hilden (Fabricius Hildanus), often called the father of German surgery, described use of a stick to twist a circumferentially constrictive bandage in amputation surgery. The stick, sometimes called a Spanish windlass, acted as a means to gain mechanical advantage in tightening [13].

As a class, the advantages of direct compression dressings are:

1) The specific location of blood loss need not be located and specifically treated.

2) Application proficiency (without specific regard to the extent of compression desired) need not be beyond that of an inexperienced novice.

The disadvantages are:

1) Feasible for treating blood from limbs only and provided the bleeding source is distal enough to leave room for the tourniquet application proximal to this region.

2) If not applied with sufficient pressure above systolic blood pressure- bleeding loss may be enhanced by reduction of venous return from the constriction performed. Therefore experience is needed to get the feel of the extent of pressure needed in order to achieve the purpose of arresting all circulation to the distal limb.

3) Extended periods of tourniquet application with high necessary pressures to completely deny blood supply to distal soft tissue will lead to ischemia and eventual infarction.

4) Tying or fastening mechanism is always necessary to maintain pressure until definitive treatment in an environment where it is possible to perform controlled wound review under illumination and suturing of damaged vessels.

5) By definition, if the trauma victim is alert, the application of the tourniquet will be exquisitely painful and this suffering will continue until complete removal.

6) Issue of nerve damage is unique to this approach.

Despite earlier dispute regarding the safety and efficacy of tourniquet use in principle, this calamity has resolved with time. Kragh et al. excellently reviewed the resurrection of tourniquet use across history and recall the first detailed tourniquet case series that from 2003 [12]. Lakstein et al. reported their experience from 1997 to 2001 of 91 casualties where tourniquets were applied prehospital. It must be stressed that the devices used were either an improvised stick with a cloth or a simple silicone elastic strip, repeatedly stretched and wrapped around the limb with regular knots tied at the ends [14]. Inherently, these methods suffer the inferiority of inconvenience because of slipping and cumbersome fastening technique. However, the investigators reported generally 
favorable results. No deaths occurred, but 5.5\% had nerve palsy. This series was not compared to a control group such that survival benefit cannot be derived from this. Later this same year tourniquet designs were screened and tested for Operation Iraqi Freedom [15]. It was later recommended the Combat Application Tourniquet (CAT; North American Rescue, Greer, SC) as standard issue to deploying US servicepersons [15]. In 2004, Alec Beekley, a general surgeon, began a study at the emergency department of the coalition's combat support hospital in Baghdad. Beekley et al. [16] reported in 2008 that prehospital tourniquet use was associated with better hemorrhage control rates, particularly in the more severely injured casualties: Kragh et al. [17] [18] reported a 2006 study of different casualties with mild, temporary, and infrequent morbidity with tourniquet use in a large cohort. The work was fruitful and evidence yielded practical guidelines, such as well-designed and tested devices performing best and improved effectiveness of tourniquet use side-by-side if one was not effective [18]. The survival rates were higher with prehospital use versus hospital use ( $89 \%$ vs $78 \%$ ), higher with use before shock onset versus after shock onset ( $96 \%$ vs $4 \%$ ), and higher with tourniquet use versus without tourniquet use ( $87 \%$ vs $0 \%)$ [17]. This high-quality dataset indicated that, in war casualties within a comprehensive trauma system, the survival rate was higher with tourniquet use than without.

In summary, these studies showed that the right tourniquets used at the right time in the right way for the right casualties saved lives! By 2008 tourniquets became a prehospital intervention evidenced strongly to be lifesaving for limb injured casualties [19]. These developments stimulated recent reconsideration of a selective role for tourniquets in civilian trauma [20].

Of a large number of versions of existing tourniquets Kragh et al. thoroughly examined the experience with three outstanding products [21]. Not surprisingly one of the conclusions reached in their assessment was that one-hand-application potential of the device confers no benefit in treatment stations or emergency departments. Furthermore this added no benefit in the field regarding significant survival advantage.

The Emergency Medical Tourniquet (EMT) designed and distributed by Delfi Medical Innovations (Vancouver, BC, Canada), was invented by a team led by James A. McEwen and made by a company with extensive organizational expertise in designing tourniquets for elective use in the operating room. The company is led by a clinical engineer, and the EMT is manufactured in a surgical tourniquet manufacturing facility with extensive quality control measures. The EMT device is a pneumatic tourniquet that has a bladder that goes around the limb, a clamp that limits the inflated portion while holding the bladder close to the limb, and an inflator bulb with connector tube and twist cap. The bladder, $88 \mathrm{~mm}$ wide, has midpoint spot welds so that the cuff lies flat and wide on the skin and does not become torus shaped and roll down the limb. These features make it similar to a blood pressure cuff except for the clamp. The EMT clamp is precision-milled; has individual device serial numbers; and is designed for use in hospitals, clinics, or ambulances.

The special operation forces tactical tourniquet (SOF-TT) consists of a 3/2" tourniquet strap providing a wide compression pattern. This broader compression pattern allows for increased patient comfort and additional arterial compression. The tourniquet handle is machined from a single piece of high strength aluminum bar stock. The snap-lock buckle design, allows re-routing of the band around trapped limbs without rethreading. The lighter weight alloy components, provide required strength and durability. The SOF-TT's promising characteristics led to its inclusion with deployed US armed forces and were included in the abovementioned assessment [21].

The Combat Application Tourniquet CAT was invented by military medics in an Afghanistan cave, the company that distributes it is run by former military medics, and the CAT is assembled in a sewing and assembly shop dedicated solely to this device. It was developed by Composite Resources, Inc. and is used by the US and Coalition military to provide soldiers a small, effective tourniquet in field combat situations, and is also in use by NHS ambulance services, and some UK fire and rescue services. The CAT utilizes a durable windlass system with a free-moving internal band with a Velcro fastening system providing circumferential pressure to the extremity. Once adequately tightened a hook and loop windlass retention strap is then applied, securing the windlass to maintain pressure during casualty evacuation. The CAT's dual securing system avoids the use of screws and clips which can become difficult to operate under survival stress or where fine motor skills are compromised.

The CAT's effectiveness rate was the highest of the field tourniquets at $79 \%$ in stopping compressible bleeding on the battlefield [18] and therefore this is the device of choice in this class.

\section{Hemostatic Dressings}

As opposed to the others, this is a completely novel group of agents which has emerged fairly recently and has 
been thoroughly subject to research of the past 15 - 20 years. The reason for this is probably the backing of industry because of the financial interest in this promising technology. A full account of almost all members of this category are reviewed because these new products are less known. Agents intended for the treatment of external bleeding can be categorized into dressings or granular/powder products.

As a class, the advantages of hemostatic dressings are:

1) Broad spectrum of body regions where it is applicable, since the mechanism is clotting propagation bleeding control this can be achieved provided a confined compartment exists.

2) Pressure is needed inasmuch as to control blood flow upon contact with wound but treatment success is not dependent on extent of manual pressure.

3) Application proficiency need not be beyond that of an inexperienced novice.

The disadvantages are:

1) The precise locus of the bleeding wound must be accurately located and covered.

2) All of these agents lack a means of application and adherence to the wound surface and therefore require neutralization of the caregiver to press the hemostatic agent against the wound until hemostasis takes effect. This may not be feasible in combat situations. (A rare instance where the wound has created a deep cavity may enable packing with gauze impregnated haemostatic agent).

3) Particular attention needed for surveillance of wound since movement or friction may dislodge clot and result in bleeding recurrence even after full bleeding control.

4) The relatively high cost of most of these products may limit their acceptance.

Dubik and Keirabadi have not only summarized these hemostatic agents in a comprehensive review but they have also thoroughly tested the various products themselves. As shown not all efforts were rewarded by success. Firstly, Stasilon (Entegrion Co, Chapel Hill, North Carolina) a non chitosan material made of a dual-fiber dressing consisting of type $\mathrm{E}$ continuous filament glass and a specialty rayon material woven together as a special textile material. Laboratory work did not find the dressing successful in stopping arterial hemorrhage and therefore this may seem more suitable for burn wound coverage.

Chitosan, deacetylated chitin derived from the shells of shrimp or other shellfish is a nontoxic and biodegradable substance with strong muco-adhesive properties suitable for hemostatic treatment. Thus, HemCon dressing, the newer Chitoflex dressing and Celox, appears to act primarily by tissue adherence and coverage of wounds.

TraumaStat, which was a dressing of nonwoven porous polyethylene fibers (high surface area) filled with precipitated silica. These filled fibers were impregnated with a chitosan derivative. Although was reported to be more effective than HC dressing in stopping bleeding in a swine femoral artery transaction model [22], this product never reached the commercial market.

HemCon bandage laboratory testing originally demonstrated efficacy in a swine grade V liver injury [23]. However in studies with the final product it produced hemostasis only briefly in $71 \%$ of swine subjected to an aortotomy injury [24], and it failed consistently to stop bleeding in a femoral artery injury model in swine [25].

Rapid Deployed Hemostatic (RDH) dressing is a chitin-based product composed of poly-N-acetyl-glucosamine (p-GlcNAc) which is fully acetylated and lyophilized, but it is algae-derived. Red blood cell and platelet aggregation, activation of the clotting cascade, and local vasoconstriction have been suggested as the mechanism behind its action. In large animals, in both aortotomy and Grade V liver injury studies, the original RDH dressing was found ineffective in controlling [26] [27]. However, a modified version of RDH (mRDH) was reported to be effective in similar models by another group [28]-[30], but it did not stop bleeding in a mixed bleeding groin injury [31].

As other products Celox (CX), was developed as a powder form of different types of chitosan. It relies on binding to negatively charged surfaces such as red blood cells and adhering to tissue at the site of injury. Besides the dry powder, Celox is also packaged in small packets that dissolve upon contact with blood, releasing the Celox powder.

The original Quick Clot (QC) hemostatic agent was composed of zeolite granules which is an aluminosilicate. When poured into a bleeding wound, it absorbs water, concentrating erythrocytes, platelets, and clotting factors in the wound, thereby promoting coagulation. During experimentation a major safety concern recognized was the exothermic reaction produced which resulted in significant thermal tissue damage in the wound in both animal experiments and combat casualties [32] [33]. Consequently, the original QC granules were no longer produced by the manufacturer (Z-Medica, Wallingford, Connecticut). The product was replaced by a safer QC product (QuikClot ACS+) without heat production upon mixture with blood composed of synthetic zeolite beads 
that are packaged in small porous cotton bags for easy application and removal from the wound [34].

In a swine groin injury model with complete transection of the femoral artery and vein, CX was shown to be as effective as QC and HC in preventing rebleeding, and significantly better than standard gauze treatment [35]. Another pig study comparing granular agents, CX supported the survival of $60 \%$ of animals by stopping arterial hemorrhage while HC and QC (ACS+) were only effective in 10\% of the cases [36].

Attending surgeons reported either stopped or greatly decreased bleeding in $95 \%$ of 40 surviving patients treated with the HemCon bandage applied to extremity wounds [37]. While the original QC was found to be effective against severe venous (Grade V Liver injury) and low pressure mixed hemorrhage from the groin, reducing both blood loss and mortality rates in swine [31] [38] [39]. This was not the case with high arterial pressure bleeding where it failed to show significant benefit [25]. Still noteworthy is that new formulations of QC with no heat generation (ACS+) have not been found effective against arterial bleeding.

A rolled, non-woven medical gauze (50\% polyester and 50\% rayon) impregnated with a contact (intrinsic) pathway activating clotting agent, kaolin is the Combat Gauze, produced by Z-Medica, Wallingford, CT. The X-Sponge, one of such products proved efficacious in bleeding pig models [40]. Similarly, Combat Gauze faired equally well in similar swine testing resulting in an $80 \%$ survival rate [41]. Efficacy and safety profiles are established in femoral and carotid artery, as well as jugular vein injury models [42] [43], but clinical experience is not available as of yet.

WoundStat (WS) is an example of aluminum phyllosilicate products that received FDA clearance for treating external bleeding. It is composed of smectite granules, that swell by granule water absorbance and form a clay material with high plasticity that adheres to tissue and can seal bleeding sites. In addition to concentrating clotting factors and blood cells, the granules have a negative electrostatic charge that activates the intrinsic pathway and accelerates the blood clotting process. WS was shown to have procoagulant activity in a human blood clotting assay [44]. This agent was $100 \%$ successful in stopping arterial hemorrhage and preventing exsanguination where other products failed [36] [45].

The Fibrin Sealant Dressing is composed of fibrinogen and thrombin derived from human plasma. As the dressing comes in contact with blood, the protein layer dissolves and fibrinogen polymerization occurs forming an adhesive fibrin layer that conforms and attaches tightly to the wound, thereby stopping bleeding. Packing for treating a grade V liver injury in coagulopathic swine, the Fibrin Patch dressing was demonstrated as both efficacious and safe [46]. Similar results were observed with this dressing in a number of large animal hemorrhage studies involving various sorts of operations [47]-[55]. A newer version of the FSD was found to be more efficacious than Combat Gauze or WoundStat in a coagulopathic swine groin arterial hemorrhage experiment [56]. To date, the fibrinogen-based dressings have been the most efficacious with an excellent long-term safety profile, therefore this agent stands out as the product of choice from the class of hemostatic agents.

\section{Direct Compression Dressings}

As a class this technique has suffered ignorance and received least attention for unknown reasons. The concept of applying external force to overcome underlying vascular hydrostatic pressures and thus arrest blood loss is the most straightforward logical approach. Nevertheless this option has been subject of least research or investigation of any sort. Reviews covering the whole issue of bleeding control often omit this option completely [57] [58] Perhaps the low technology leading to potentially small profit margins or general pessimism regarding success with this approach deems this procedure unattractive. However advance has been made in this field and this topic seems more than worthy of discussion. In any chosen configuration of this group the surface area of the wound must be directly covered by the dressing.

\subsection{Manual Pressure}

Partial Hemorrhage control may be achieved by the application of direct pressure on the bleeding site. When possible, this may be combined with elevation of the bleeding site above the level of the heart, which lowers the pressure at the point of bleeding. Performing this manually as previously advocated in the past (ATLS manual) by pressing 4X4 guaze pads will prove less effective as the extent of force will alter over time. Manual external compression is cumbersome, unreliable and difficult to maintain over an extended period of time [59]. This will also neutralize the caregiver completely. Nevertheless, as a temporary solution, it may partly curb immediate blood loss until an alternative approach is chosen. 
As a class, the advantages of direct compression dressings are:

1) Relevant to diverse body regions even torso (wounds overlying pelvic or scapular bones) if occlusive methods allow firm pressure exertion.

2) Application proficiency (without specific regard to the extent of compression desired) need not be beyond that of an inexperienced novice.

3) May prove to be even faster than tourniquet application in certain instances.

4) Will not deteriorate victim's condition if inexperienced personnel place too softly.

5) If produced with transparent material can lead superiority in wound surveillance throughout evacuation.

6) The specific location of blood loss need not be located providing a genuine closed compartment can be created surrounding the wound area and lead to environmental tamponade.

7) When produced with cohesive materials slipping is prevented and no tying mechanism is necessary.

8) As a rule, all members of this category are relatively inexpensive since raw materials and assembly remain simple and not costly.

The disadvantages are:

1) Futile for regions that are non compressible.

2) If not applied with sufficient pressure the dressing will not be effective.

3) Extended periods of application can cause tissue maceration.

4) Some body region dressing may be time consuming.

5) If circumferential pressure is applied maximally the tourniquet effect may be reached even where not necessarily needed.

\subsection{Field Bandage}

The "Army Field Bandage" (as it is called) was the mainstay to control external bleeding before and throughout the world wars until currently in most armies. It is composed of a thick layer of absorbent cotton that is wrapped in layers of gauze and attached to two long straps for wrapping around the wound. It absorbs large volumes of blood and provides a matrix that promotes platelet aggregation and blood coagulation while exerting pressure on the wound. It seems astounding that for a procedure lasting a century long as far as can be accessed no single study was ever dedicated solely to investigate the merits of this device. In one single publication, this device was used in the control arm and found to be fairly useless as exerted pressures over almost all body parts hardly reached near to prevailing diastolic blood pressure [60]. Placing a solid, rigid object underneath the pad added nothing to the negligible pressures. The fact that the contact component is produced in a manner to absorb blood is a further disadvantage since the amount of blood loss or ongoing hemorrhaging is impossible to assess in this manner.

Many dressings have appeared on the market, but few even claim to apply pressure over the bleeding wound surface. Three different configurations were chosen to represent this group.

\subsection{Emergency Bandage}

This product is also termed in lay literature: “The Israeli Bandage” and manufactured by Firstcare inc. The ingenuity of its invention was reached by a military medic sent to combat with a 1942 designed field bandage who felt ridiculous carrying primitive equipment. The emergency bandage is an elasticized bandage with a non- adhesive bandage pad sewn in. The pad absorbs up to 500 cc of blood. The bandage has a built-in pressure bar, which allows those handling it to twist the bandage around the wound once, and then change the direction of the bandage, wrapping it around the limb or body part, to create pressure on the wound. The pressure bar is also assumed to increase localized pressure. A closure clip at the end of the bandage is intended to retain stretched flaps in place and prevent slipping and recoiling of the dressing. The bandages come in three different sizes: 4, 6 , and 8 inches wide. They are similar to domestic elastic (“ACE”) bandages that are used to treat sprain injuries, but they have three features that are unique to them: 1) A sterile non-adhering dressing that is designed to allow removing the bandage without reopening the wound. 2) A pressure applicator or pressure bar that is placed directly over the wound to stop the bleeding by applying pressure. It allows to rap the bandage around a wound in different directions. This is a useful feature for stopping bleeding in groin and head injuries. A closure bar that is used to secure the bandage and to apply additional pressure to a wound.

The doubling back within the rigid polymer "bar" makes bandaging somewhat clumsy, the absorption and 
opacity disallows assessment of blood loss or success at bleeding control. Nevertheless, this product is far advanced than previous tied dressings and has penetrated a number of medical systems and combat units with growing popularity. In laboratory conditions the device exhibited satisfactory compression pressures over a number of body sites [61] with added benefit of the "so-called" pressure bar. However this data contradicts previous exploration of this phenomenon conceptually [3]. Further studies are needed to elucidate this point one way or the other. There are no reports of clinical experience with this device.

\subsection{The Cinchtight Dressing}

A display of medical devices and bandages are manufactured by "H \& $\mathrm{H}$ medical inc."

This device termed a compression dressing appears in standard to very large 12 " $\times 16$ ” pad areas capable of covering the largest wound areas. The acclaimed purpose of this is not only to protect underlying vital organs but also to exert pressure to stem blood loss. It secures to the abdominal (or other) wound with over 5 feet of strengthened elastic wrap sewn onto the large pad. In one configuration, a metal hook on the pad back affords the possibility to double back and wrap the bandage in a countered clockwise direction and exert pressure while preventing slipping at the same time. The materials comprising the pad attached to the surface of the wound stretch with vigorous pressure exertion and therefore an extent of dislodgement is feared in the course of dressing the wound. In addition, high pressures are difficult to attain since the fastening method precludes continuation of the tightening process, therefore anywhere but a cylindrical distal limb can we expect satisfactory control. There is no literature on laboratory or field testing of this device.

\subsection{Elastic Adhesive Dressing (ELAD)}

This device arose to control bleeding from both military and civilian victims in a region heavily stricken by terror activity. After previous experimentation with elastic bandages with a glue interface [62] or materials such as Coban, the teams, perfecting infusion drip fixation tubing techniques, applied their successes to wounds with a tailored transparent polyethylene strip [63]. The ELAD constitutes of an elastic bandage with cohesive properties that enhances pressure, avoids wrapped layer slipping and is immediately affixed in position with obviation of a fastening mechanism when full compression is achieved. This dressing consists of a non absorbent indicator pad component, produced such that if inappropriately dressed it will absorb only a minimal amount of blood before becoming saturated and this will be visualized through the transparent bandaged layers. The strip component incorporated in the device consists of resilient material durable enough such that it won't tear upon traction, though elastic to the extent of allowing easy stretching across the body surface. Laboratory testing results include both satisfactory exertion of pressures across body areas and demonstrated convenient to use by diverse medical teams [60]. This product has not reached the market to date but it was distributed to a number of medical systems for experimentation. A published series of 62 cases with 87\% full control of bleeding [64] included an outstanding case of a combat soldier presenting with a complex facial injury [65]. The dressing sealed the whole bleeding area leading to eventual survival. Especially if combined with a hemostatic pad this may confer it applicable to most all body surfaces and turn into a leading product in the future.

From this class, elastic adhesive dressings appear most tempting since they are quickest to apply and are especially effective in awkward proximal compressible regions, however proprietary products such as $\operatorname{Coban}^{\mathrm{R}}$ and Coflex ${ }^{\mathrm{R}}$ are not even marketed for use in trauma and have torn in the process of tight compression bandaging. Therefore the product of choice in this group would be the Emergency Bandage.

\section{Conclusion}

Trauma patients have been bleeding to death for thousands of years. The methods used to control hemorrhage (tourniquets, pressure, bandages, and ligatures) have not changed but progress in technology has brought about interesting insights. A logical set approach is needed to match available products to the presenting injury. A suggested guideline would be to dress the wound in a compressible body area with a direct compression dressing since for such regions there is no evidence that hemostatic agents hold any advantage (although even animal side by side trials have not been conducted yet). The hemostatic agents should be applied over the awkward non cylindrical zones still amenable to external access providing there is ample time for their application. Owing to the possible tissue damage and severe discomfort caused by tourniquets, these should be used as last resort only and 
these should be removed as early as possible. Events where tourniquets are especially advocated would be wounded distal limbs when the precise bleeding site is not identified (as a mangled limb or amputation).

\section{Disclosure of Conflicts of Interest}

The author has personally initiated trials and published reports regarding the ELAD device which is not a commercial entity at this point.

\section{References}

[1] Bellamy, R.F. (1984) Causes of Death in Conventional Warfare: Implications for Combat Casualty Care Research. Military Medicine, 149, 55-62.

[2] Acosta, J.A., Yang, J.C., Winchell, R.J., Simons, R.K., Fortlage, D.A., Hollingsworth-Fridlund, P. and Hoyt, D.A. (1998) Lethal Injuries and Time to Death in a Level One Trauma Center. Journal of the American College of Surgeons, 186, 528-533. http://dx.doi.org/10.1016/S1072-7515(98)00082-9

[3] Sauaia, A., Moore, F.A., Moore, E.E., Moser, K.S., Brennan, R., Read, R.A. and Pons, P.T. (1995) Epidemiology of Trauma Deaths: A Reassessment. Journal of Trauma, 38, 185-193. http://dx.doi.org/10.1097/00005373-199502000-00006

[4] Shackford, S.R., Mackersie, R.C., Holbrook, T.L., Davis, J.W., Hollingsworth-Fridlund, P., Hoyt, D.B. and Wolf, P.L. (1993) The Epidemiology of Traumatic Death: A Population-Based Analysis. Archives of Surgery, 128, 571-575. http://dx.doi.org/10.1001/archsurg.1993.01420170107016

[5] Regel, G., Stalp, M., Lehmann, U. and Seekamp, A. (1997) Prehospital Care, Importance of Early Intervention on Outcome. Acta Anaesthesiologica Scandinavica, S110, 71-76. http://dx.doi.org/10.1111/j.1399-6576.1997.tb05508.x

[6] Bellamy, R.F. (1995) Combat Trauma Overview. In: Zajtchuk, R., Bellamy, R.F., Grande, C.M., Eds., Anesthesia and Perioperative Care of the Combat Casualty: Textbook of Military Medicine, Office of the Surgeon General, Falls Church, 1-42.

[7] Gofrit, O.N., Leibovici, D., Shapira, S., Shemer, J., Stein, M. and Michaelson, M. (1997) The Trimodal Death Distribution of Trauma Victims: Military Experience from the Lebanon War. Military Medicine, 162, 24-26.

[8] Scope, A., Farkash, U., Lynn, M., Abargel, A. and Eldad, A. (2001) Mortality Epidemiology in Low-Intensity Warfare: Israel Defense Forces’ Experience. Injury, 32, 1-3. http://dx.doi.org/10.1016/S0020-1383(00)00101-7

[9] Owens, B.D., Kragh, J.F., Wenke, J.C., Macaitis, J., Wade, C.E. and Holcomb, J.B. (2008) Combat Wounds in Operation Iraqi Freedom and Operation Enduring Freedom. Journal of Trauma, 64, 295-299. http://dx.doi.org/10.1097/TA.0b013e318163b875

[10] Ryan, K.L., Kheirabadi, B.S., Klemcke, H.G., Martini, W., Delgado, A.V. and Pusateri, A.E. (2003) Overview of the Hemostasis Research Program: Advances and Future Directions. The RTOHFM Symposium on Combat Casualty Care in Ground Based Tactical Situations, St. Pete Beach, 2003.

[11] Kelly, J.F., Ritenour, A.E., McLaughlin, D.F., Bagg, K.A., Apodaca, A.N., Mallak, C.T., Pearse, L., Lawnick, M.M., Champion, H.R., Wade, C.E. and Holcomb, J.B. (2008) Injury Severity and Causes of Death from Operation Iraqi Freedom and Operation Enduring Freedom: 2003-2004 versus 2006. Journal of Trauma, 64, S21-S27. http://dx.doi.org/10.1097/TA.0b013e318160b9fb

[12] Kragh, J.F. Jr., Swan, K.G., Smith, D.C., Mabry, R.L. and Blackbourne, L.H. (2012) Historical Review of Emergency Tourniquet Use to Stop Bleeding. The American Journal of Surgery, 203, 242-252. http://dx.doi.org/10.1016/j.amjsurg.2011.01.028

[13] Pilcher, L.S. (1899) Treatment of Wounds: Its Principles and Practice, General and Special. 2nd Edition, William Wood, New York.

[14] Lakstein, D., Blumenfeld, A., Sokolov, T., Lin, G., Bssorai, R., Lynn, M. and Ben-Abraham, R. (2003) Tourniquets for Hemorrhage Control on the Battlefield: A 4-Year Accumulated Experience. Journal of Trauma, 54, S221-S225.

[15] Walters, T.J., Wenke, J.C., Kauvar, D.S., McManus, J.G., Holcomb, J.B. and Baer, D.G. (2005) Effectiveness of Self-Applied Tourniquets in Human Volunteers. Prehospital Emergency Care, 9, 416-422. http://dx.doi.org/10.1080/10903120500255123

[16] Beekley, A.C., Sebesta, J.A., Blackbourne, L.H., Herbert, G.S., Kauvar, D.S., Baer, D.G., Walters, T.J., Mullenix, P.S. and Holcomb, J.B. of 31st Combat Support Hospital Research Group. (2008) Prehospital Tourniquet Use in Operation Iraqi Freedom: Effect on Hemorrhage Control. Journal of Trauma, 64, S28-S37. http://dx.doi.org/10.1097/TA.0b013e318160937e

[17] Kragh, J.F. Jr., Walters, T.J., Baer, D.G., Fox, C.J., Wade, C.E., Salinas, J. and Holcomb, J.B. (2009) Survival with 
Emergency Tourniquet Use to Stop Bleeding in Major Limb Trauma. Annals of Surgery, 249, 1-7. http://dx.doi.org/10.1097/SLA.0b013e31818842ba

[18] Kragh Jr., J.F., Walters, T.J., Baer, D.G., Fox, C.J., Wade, C.E., Salinas, J. and Holcomb, J.B. (2008) Practical Use of Emergency Tourniquets to Stop Bleeding in Major Limb Trauma. Journal of Trauma, 64, S38-S50. http://dx.doi.org/10.1097/TA.0b013e31816086b1

[19] Moore, F.A. (2009) Tourniquets: Another Adjunct in Damage Control? Annals of Surgery, 249, 8-9. http://dx.doi.org/10.1097/SLA.0b013e3181932329

[20] Cain, J.S. (2008) From the Battlefield to Our Streets: How Combat Medicine Is Revolutionizing Civilian Prehospital Care. Journal of Trauma: War Trauma, 3, 16-23.

[21] Kragh Jr., J.F., O’Neill, M.L., Walters, T.J., Dubick, M.A., Baer, D.G., Wade, C.E., Holcomb, J.B. and Blackbourne, L.H. (2011) The Military Emergency Tourniquet Program's Lessons Learned with Devices and Designs. Military Medicine, 176, 1144-1152. http://dx.doi.org/10.7205/MILMED-D-11-00114

[22] Englehart, M.S., Cho, S.D., Tieu, B.H., Morris, M.S., Underwood, S.J., Karahan, A., Muller, P.J., Differding, J.A., Farrell, D.H. and Schreiber, M.A. (2008) A Novel Highly Porous Silica and Chitosan-Based Hemostatic Dressing Is Superior to HemCon and Gauze Sponges. Journal of Trauma, 65, 884-892. http://dx.doi.org/10.1097/TA.0b013e318187800b

[23] Pusateri, A.E., McCarthy, S.J., Gregory, K.W., Harris, R.A., Cardenas, L., McManus, A.T. and Goodwin Jr., C.W. (2003) Effect of a Chitosan-Based Hemostatic Dressing on Blood Loss and Survival in a Model of Severe Venous Hemorrhage and Hepatic Injury in Swine. Journal of Trauma, 54, 177-182. http://dx.doi.org/10.1097/00005373-200301000-00023

[24] Kheirabadi, B.S., Acheson, E.M., Deguzman, R., Sondeen, J.L., Ryan, K.L., Delgado, A., Dick Jr., E.J. and Holcomb, J.B. (2005) Hemostatic Efficacy of Two Advanced Dressings in an Aortic Hemorrhage Model in Swine. Journal of Trauma, 59, 25-35. http://dx.doi.org/10.1097/01.TA.0000171458.72037.EE

[25] Acheson, E.M., Kheirabadi, B.S., Deguzman, R., Dick Jr., E.J. and Holcomb, J.B. (2005) Comparison of Hemorrhage Control Agents Applied to Lethal Extremity Arterial Hemorrhage in Swine. Journal of Trauma, 59, 865-875. http://dx.doi.org/10.1097/01.ta.0000187655.63698.9f

[26] Pusateri, A.E., Modrow, H.E., Harris, R.A., Holcomb, J.B., Hess, J.R., Mosebar, R.H., Reid, T.J., Nelson, J.H., Goodwin Jr., C.W., Fitzpatrick, G.M., McManus, A.T., Zolock, D.T., Sondeen, J.L., Cornum, R.L. and Martinez, R.S. (2003) Advanced Hemostatic Dressing Development Program: Animal Model Selection Criteria and Results of a Study of Nine Hemostatic Dressings in a Model of Severe Large Venous Hemorrhage and Hepatic Injury in Swine. Journal of Trauma, 55, 518-526. http://dx.doi.org/10.1097/01.TA.0000075336.92129.27

[27] Sondeen, J.L., Pusateri, A.E., Coppes, V.G., Gaddy, C.E. and Holcomb, J.B. (2003) Comparison of 10 Different Hemostatic Dressing in an Aortic Injury. Journal of Trauma, 54, 280-285. http://dx.doi.org/10.1097/01.TA.0000037431.19185.B4

[28] Connolly R.J. (2004) Application of the Poly-N-Acetyl Glucosamine-Derived Rapid Deployment Hemostat Trauma Dressing in Severe/Lethal Swine Hemorrhage Trauma Models. Journal of Trauma, 57, S26-S28. http://dx.doi.org/10.1097/01.TA.0000136746.97192.B2

[29] Vournakis, J.N., Demcheva, M., Whitson, A.B., Finkielsztein, S. and Connolly, R.J. (2003) The RDH Bandage: Hemostasis and Survival in a Lethal Aortotomy Hemorrhage Model. Journal of Surgical Research, 113, 1-5. http://dx.doi.org/10.1016/S0022-4804(03)00161-6

[30] Jewelewicz, D.D., Cohn, S.M., Crookes, B.A. and Proctor, K.G. (2003) Modified Rapid Deployment Hemostat Bandage Reduces Blood Loss and Mortality in Coagulopathic Pigs with Severe Liver Injury. Journal of Trauma, 55, 275-281. http://dx.doi.org/10.1097/01.TA.0000079375.69610.89

[31] Alam, H.B., Uy, G.B., Miller, D., Koustova, E., Hancock, T., Inocencio, R., Anderson, D., Llorente, O. and Rhee, P. (2003) Comparative Analysis of Hemostatic Agents in a Swine Model of Lethal Groin Injury. Journal of Trauma, 54, 1077-1082. http://dx.doi.org/10.1097/01.TA.0000068258.99048.70

[32] Wright, J.K., Kalns, J., Wolf, E.A., Traweek, F., Schwarz, S., Loeffler, C.K., Snyder, W., Yantis Jr., L.D. and Eggers, J. (2004) Thermal Injury Resulting from Application of a Granular Mineral Hemostatic Agent. Journal of Trauma, 57, 224-230. http://dx.doi.org/10.1097/01.TA.0000105916.30158.06

[33] Rhee, P., Brown, C., Martin, M., Salim, A., Plurad, D., Green, D., Chambers, L., Demetriades, D., Velmahos, G. and Alam, H. (2008) QuickClot Use in Trauma for Hemorrhage Control: Case Series of 103 Documented Uses. Journal of Trauma, 64, 1093-1099. http://dx.doi.org/10.1097/TA.0b013e31812f6dbc

[34] Arnaud, F., Tomori, T., Saito, R., McKeague, A., Prusaczyk, W.K. and McCarron, R.M. (2007) Comparative Efficacy of Granular and Bagged Formulations of the Hemostatic Agent QuickClot. Journal of Trauma, 63, 775-782. http://dx.doi.org/10.1097/TA.0b013e31805f7023 
[35] Kozan, B.G., Kircher, S.J., Henao, J., Godinez, F.S. and Johnson, A.S. (2008) An Alternative Hemostatic Dressing: Comparison of CELOX, HemCon, QuikClot. Academic Emergency Medicine, 15, 74-81. http://dx.doi.org/10.1111/j.1553-2712.2007.00009.x

[36] Kheirabadi, B.S., Edens, J.W., Terrazas, I.B., Estep, J.S., Klemcke, H.G., Dubick, M.A. and Holcomb, J.B. (2009) Comparison of New Hemostatic Granules/Powders with Currently Deployed Hemostatic Products in a Lethal Model of Extremity Arterial Hemorrhage in Swine. Journal of Trauma, 66, 316-328. http://dx.doi.org/10.1097/TA.0b013e31819634a1

[37] Cox, E.D., Schreiber, M.A., McManus, J., Wade, C.E. and Holcomb, J.B. (2009) New Hemostatic Agents in the Combat Setting. Transfusion, 49, 248S-255S. http://dx.doi.org/10.1111/j.1537-2995.2008.01988.x

[38] Pusateri, A.E., Delgado, A.V., Dick Jr., E.J., Martinez, R.S., Holcomb, J.B. and Ryan, K.L. (2004) Application of a Granular Mineral-Based Hemostatic Agent (QuikClot) to Reduce Blood Loss After Grade V Liver Injury in Swine. Journal of Trauma, 57, 555-562. http://dx.doi.org/10.1097/01.TA.0000136155.97758.CD

[39] Alam, H.B., Chen, Z., Jaskille, A., Querol, R.I., Koustova, E., Inocencio, R., Conran, R., Seufert, A., Ariaban, N., Toruno, K. and Rhee, P. (2004) Application of a Zeolite Hemostatic Agent Achieves 100\% Survival in a Lethal Model of Complex Groin Injury in Swine. Journal of Trauma, 56, 974-983. http://dx.doi.org/10.1097/01.TA.0000127763.90890.31

[40] Arnaud, F., Parreño-Sadalan, D., Tomori, T, Delima, M.G., Teranishi, K., Carr, W., McNamee, G., McKeague, A., Govindaraj, K., Beadling, C., Lutz, C., Sharp, T., Mog, S., Burris, D. and McCarron, R. (2009) Comparison of 10 Hemostatic Dressings in a Groin Transection Model in Swine. Journal of Trauma, 67, 848-855. http://dx.doi.org/10.1097/TA.0b013e3181b2897f

[41] Shires, G.T. (1979) Care of the Trauma Patient. McGraw-Hill Inc., New York, 132-136.

[42] Kheirabadi, B.S., Scherer, M.R., Estep, J.S., Dubick, M.A. and Holcomb, J.B. (2009) Determination of Efficacy of New Hemostatic Dressings in a Model of Extremity Arterial Hemorrhage in Swine. Journal of Trauma, 67, 450-460. http://dx.doi.org/10.1097/TA.0b013e3181ac0c99

[43] Kheirabadi, B.S., Mace, J.E., Terrazas, I.B., Fedyk, C.G., Estep, J.S., Dubick, M.A. and Blackbourne, L.H. (2010) Safety Evaluation of New Hemostatic Agents, Smectite Granules and Kaolin-Coated Gauze in a Vascular Injury Wound Model in Swine. Journal of Trauma, 68, 269-278.

[44] Moskowitz, K.A., Manly, D.A. and Mackman, N. (2009) Effect of a Topical Hemostatic Agent on Clotting Times in a Whole Blood Model of Dilutional Coagulopathy. Journal of Thrombosis and Haemostasis, 7, PP-TH-678.

[45] Ward, K.R., Tiba, M.H., Holbert, W.H., Blocher, C.R., Draucker, G.T., Proffitt, E.K., Bowlin, G.L., Ivatury, R.R. and Diegelmann, R.F. (2007) Comparison of a New Hemostatic Agent to Current Hemostatic Agents in a Swine Model of Lethal Extremity Arterial Hemorrhage. Journal of Trauma, 63, 276-283. http://dx.doi.org/10.1097/TA.0b013e3180eea8a5

[46] Delgado, A.V., Kheirabadi, B.S., Fruchterman, T.M., Scherer, M., Cortez, D., Wade, C.E., Dubick, M.A. and Holcomb, J.B. (2008) A Novel Biologic Hemostatic Dressing (Fibrin Patch) Reduces Blood Loss and Resuscitation Volume and Improves Survival in Hypothermic, Coagulopathic Swine with Grade V Liver Injury. Journal of Trauma, 64, 75-80. http://dx.doi.org/10.1097/TA.0b013e31815b843c

[47] Larsen, M.J., Bowersox, J.C., Lim, R.C. and Hess, J.R. (1995) Efficacy of a Fibrin Hemostatic Bandage in Controlling Hemorrhage from Experimental Arterial Injuries. JAMA Surgery, 130, 420-422. http://dx.doi.org/10.1001/archsurg.1995.01430040082018

[48] Jackson, M., Friedman, S.A., Carter, A.J., Bayer, V., Burge, J.R., MacPhee, M.J., Drohan, W.N. and Alving, B.M. (1997) Hemostatic Efficacy of a Fibrin Sealant-Based Topical Agent in a Femoral Artery Injury Model: A Randomized, Blinded, Placebo-Controlled Study. Journal of Vascular Surgery, 25, 274-280. http://dx.doi.org/10.1016/S0741-5214(97)70189-7

[49] Holcomb, J., MacPhee, M., Hetz, S., Harris, R., Pusateri, A. and Hess, J. (1998) Efficacy of a Dry Fibrin Sealant Dressing for Hemorrhage Control After Ballistic Injury. JAMA Surgery, 133, 32-35. http://dx.doi.org/10.1001/archsurg.133.1.32

[50] Holcomb, J.B., Pusateri, A.E., Harris, R.A., Charles, N.C., Gomez, R.R., Cole, J.P., Beall, L.D., Bayer, V., MacPhee, M.J. and Hess, J.R. (1999) Effect of Dry Fibrin Sealant Dressings on Blood Loss in Grade V Liver Injuries in Resuscitated Swine. Journal of Trauma, 46, 49-57. http://dx.doi.org/10.1097/00005373-199901000-00009

[51] Holcomb, J.B., Pusateri, A.E., Harris, R.A., Reid, T.J., Beall, L.D., Hess, J.R. and MacPhee, M.J. (1999) Dry Fibrin Sealant Dressings Reduce Blood Loss, Resuscitation Volume, and Improve Survival in Hypothermic Coagulopathic Swine with Grade V Liver Injuries. Journal of Trauma, 47, 233-242. http://dx.doi.org/10.1097/00005373-199908000-00002

[52] Pusateri, A.E., Kheirabadi, B.S., Delgado, A.V., Doyle, J.W., Kanellos, J., Uscilowicz, J.M., Martinez, R.S., Holcomb, J.B. and Modrow, H.E. (2004) Structural Design of the Dry Fibrin Sealant Dressing and Its Impact on the Hemostatic 
Efficacy of the Product. Journal of Biomedical Materials Research Part B: Applied Biomaterials, 70B, 114-121. http://dx.doi.org/10.1002/jbm.b.30031

[53] Cornum, R., Bell, J., Gresham, V., Brinkley, W., Beall, D. and MacPhee, M. (1999) Intraoperative Use of the Absorbable Fibrin Adhesive Bandage: Long Term Effects. Journal of Urology, 162, 1817-1820. http://dx.doi.org/10.1016/S0022-5347(05)68244-4

[54] Cornum, R.L., Morey, A.F., Harris, R., Gresham, V., Daniels, R., Knight, R.W., Beall, D., Pusateri, A., Holcomb, J. and MacPhee, M. (2000) Does the Absorbable Fibrin Adhesive Bandage Facilitate Partial Nephrectomy? Journal of Urology, 164, 864-867. http://dx.doi.org/10.1016/S0022-5347(05)67328-4

[55] Morey, A.F., Anema, J.G., Harris, R., Gresham, V., Daniels, R., Knight, R.W., Beall, D., MacPhee, M. and Cornum, R.L. (2001) Treatment of Grade 4 Renal Stab Wounds with Absorbable Fibrin Adhesive Bandage in a Porcine Model. Journal of Urology, 165, 955-958. http://dx.doi.org/10.1016/S0022-5347(05)66583-4

[56] Kheirabadi, B.S., Mace, J.E., Terrazas, I.B., Fedyk, C.G., Cox, A.B., Beall, D., MacPhee, M.J., Estep, J.S., Dubick, M.A. and Blackbourne, L.H. (2010) Clot-Inducing Minerals versus Plasma Protein Dressing for Topical Treatment of External Bleeding in the Presence of Coagulopathy. Journal of Trauma, 69, 1062-1072.

[57] Blackbourne, L.H., Baer, D.G., Eastridge, B.J., Kheirabadi, B., Bagley, S., Kragh Jr., J.F., Cap, A.P., Dubick, M.A., Morrison, J.J., Midwinter, M.J., Butler, F.K., Kotwal, R.S. and Holcomb, J.B. (2012) Military Medical Revolution: Prehospital Combat Casualty Care. Journal of Trauma and Acute Care Surgery, 73, S372-S377. http://dx.doi.org/10.1097/TA.0b013e3182755662

[58] Kragh Jr., J.F., Mann-Salinas, E.A., Kotwal, R.S., Gross, K.R., Gerhardt, R.T., Kheirabadi, B., Wallum, T.E. and Dubick, M.A. (2013) Laboratory Assessment of Out-of-Hospital Interventions to Control Junctional Bleeding from the Groin in a Manikin Model. American Journal of Emergency Medicine, 31, 1276-1278. http://dx.doi.org/10.1016/j.ajem.2013.03.021

[59] Kirby, N.G. and Blackburn, G. (1981) Field Surgery Pocket Book. Her Majesty’s Stationery Office, London, 34-49.

[60] Naimer, S.A. and Neville, A. (2004) Gush Katif Rescue Team: Evaluation of Techniques for Treating the Bleeding Wound. Injury, 35, 974-979. http://dx.doi.org/10.1016/S0020-1383(03)00316-4

[61] Shipman, N. and Lessard, C.S. (2009) Pressure Applied by the Emergency/Israeli Bandage. Military Medicine, 174, 86-92. http://dx.doi.org/10.7205/MILMED-D-00-9908

[62] Naimer, S.A. and Chemla, F. (2000) Elastic Adhesive Dressing as Selected Treatment for the Bleeding Wound. American Journal of Emergency Medicine, 18, 816-819. http://dx.doi.org/10.1053/ajem.2000.18126

[63] Naimer, S. (1999) Effective Technique for Hemorrhage Control in the Emergency Situation (Letter). Harefuah, 137, 84 (in Hebrew).

[64] Naimer, S.A., Nash, M., Niv, A. and Lapid, O. (2004) Control of Massive Bleeding From Facial Gunshot Wound with a Compact Elastic Adhesive Compression Dressing. American Journal of Emergency Medicine, 22, 586-588. http://dx.doi.org/10.1016/j.ajem.2004.09.004

[65] Naimer, S.A. (2006) Gush Katif Trauma Team, Traumatic Wound Bleeding Control with a Compact Elastic Adhesive Compression Dressing. Military Medicine, 171, 644-647. 